http://jmscr.igmpublication.org/home/

ISSN (e)-2347-176x ISSN (p) 2455-0450

crossref DOI: https://dx.doi.org/10.18535/jmscr/v7i10.112

Journal Of Medical Science And Clinical Research

IGM Publication

An Official Publication of IGM Publication

\title{
An Observational Study on Microalbuminuria in Non Diabetic Acute Ischemic Stroke Patients
}

\author{
Authors \\ Dr S.Gopikumar ${ }^{1}$, Dr A. Elayaraja ${ }^{2}$, Prof. Dr K.Baburaj ${ }^{3}$, Prof. Dr M. Senthilvelan ${ }^{4}$ \\ ${ }^{1}$ Post Graduate, Department of General Medicine, Rajah Muthiah Medical College \& Hospital, \\ Annamalai University, Chidambaram, India - 608002 \\ ${ }^{2}$ Lecturer, Department of General Medicine, Rajah Muthiah Medical College \& Hospital, \\ Annamalai University, Chidambaram, India - 608002 \\ ${ }^{3}$ Professor, Department of General Medicine, Rajah Muthiah Medical College \& Hospital, \\ Annamalai University, Chidambaram, India - 608002
}

${ }^{3}$ Professor and Head, Department of General Medicine, Rajah Muthiah Medical College \& Hospital,

Annamalai University, Chidambaram, India - 608002

\begin{abstract}
Aims and Objectives: Aims and objectives of the present study were to; To assess the magnitude of Microalbuminuria in Non Diabetic acute ischemic stroke patients. The relationship between the presence of Microalbuminuria and clinical features noted in the acute ischemic stroke period. The importance of Microalbuminuria as an independent prognostic predictor in Acute ischemic stroke patient based on Scandinavian Stroke Scale.

Methods: The study was performed on patients admitted for non-diabetic acute ischemic stroke in Rajah Muthiah Medical College and Hospital under the Division of General Medicine from October 2017 to September 2019. After satisfying the inclusion and exclusion criteria 50 patients were included in this study. Their 24hrs urine microalbuminuria on the day of admission was measured. The relationship between 24 hrs urine microalbuminuria, Scandinavian Stroke Scale and non-diabetic acute ischemic stroke was observed.

Results: There was significant correlation between 24hrs urine microalbuminuria, Scandinavian Stroke Scale and non-diabetic acute ischemic stroke.

Conclusion: Microalbuminuria was present in 54\% acute ischemic stroke patients studied. Urine albumin excretion had the strongest correlation with the Scandinavian Stoke Scale of the patient in Acute Ischemic Stroke. Those with a lower Scandinavian Stroke Scale had a higher rate of urine albumin excretion and vice versa. Acute ischemic stroke patient with Microalbuminuria were significantly older than Normalbuminurics but there was no significant graded correlation of Age with urine albumin excretion in inter-group and intra-group studies. There was no significant difference in Blood Pressure in Microalbuminurics and Normalbuminurics. There was no significant correlation of Blood Pressure with Urine Albumin Excretion in acute ischemic stroke.

Keywords: Microalbuminuria, Non Diabetic acute ischemic stroke, Scandinavian Stroke Scale.
\end{abstract}

\section{Introduction}

Microalbuminuria is defined as a slight increase above normal in urinary albumin excretion ranging from 30 to $300 \mathrm{mg} / 24 \mathrm{Hrs}$. 
It is believed that persistent Microalbuminuria reflects widespread vascular damage, which can predispose patient to Atherosclerosis and it also reflects the systemic transcapillaiy leakage of albumin and is frequently accompanied by an increased activity of von Willebrand factor and / or factor VII both known to be markers of endothelial damage. ${ }^{1}$

The thickness of the intima-media complex in carotid arteries, which reflects the progression of atherosclerosis in these vessels, correlates well with the presence of Microalbuminuria.

Microalbuminuria in the non-diabetic population is associated with the loss of glomerular charge selectivity due to the loss of heparin sulfatethought to be a non-specific marker of widespread vascular damage or of endothelial dysfunction. ${ }^{2}$

This study designed to assess the magnitude of Microalbuminuria in Non Diabetic acute Ischemic Stroke patient and the significance of Microalbuminuria as a prognostic predictor in patients with Acute Ischemic Stroke. ${ }^{5}$

\section{Aims and Objectives}

The Aims and objectives of the present study were to;

- To assess the magnitude of Microalbuminuria in Non Diabetic acute ischemic stroke patients.

- The relationship between the presence of Microalbuminuria and clinical features noted in the acute ischemic stroke period.

- The importance of Microalbuminuria as an independent prognostic predictor in Acute ischemic stroke patient based on Scandinavian Stroke Scale.

\section{Materials and Methods}

\section{Study Design}

- Hospital Based Cross - Sectional Study

\section{Sample Size}

- 50 Patients with Non Diabetic Acute Ischemic Stroke and its relation with Microalbuminuria

\section{Study Duration}

- October 2017 to September 2019.

\section{Study Place}

- Patients from Rajah Muthiah Medical College \& Hospital.

\section{Study Materials \\ Selection Criteria \\ Inclusion Criteria}

- Age more than 40 years.

- Patient presented within 24 hours of onset of Acute ischemic stroke as confirmed by Computed Tomography

\section{Exclusion Criteria}

- Patients with Diabetes Mellitus

- Abnormal urine analysis findings (Hematuria, Leucocyturia, Proteinuria $>300 \mathrm{mg} / 24 \mathrm{hrs}$, Glycosuria)

- Clinical or Laboratory signs or symptoms of infection during the first day following stroke

- Renal or Hepatic failure

- Glomerulonephritis

- Known concomitant Neoplastic disease

- Those on NSAIDs or Immunosuppressant

- Patients with space occupying lesions and intra cerebral hemorrhage

\section{Patient Characteristics}

A total 50 people were included in the final analysis.

Table 1: Descriptive analysis of age group in study population $(\mathrm{N}=50)$

\begin{tabular}{||l|c|c||}
\hline Age Group & Frequency & Percentage \\
\hline Below 41 & 4 & $8 \%$ \\
\hline 41 to 50 & 13 & $26 \%$ \\
\hline 51 to 60 & 16 & $32 \%$ \\
\hline 61 to 70 & 7 & $14 \%$ \\
\hline 71 to 80 & 7 & $14 \%$ \\
\hline 81 to 90 & 3 & $6 \%$ \\
\hline Total & 30 & $100 \%$ \\
\hline
\end{tabular}

Among the study population, 4 (8\%) people were aged below 41, 13 (26\%) people were aged between 41 to $50,16(32 \%)$ people were aged between 51 to 60,7 (14\%) people were aged between 61 to 70,7 (14\%) people were aged between 71 to 80 and $3(6 \%)$ people were aged between 81 to 90 . 


\section{JMSCR Vol||07||Issue |10||Page 677-684||October}

Figure 1: Bar chart of age group distribution in study population $(\mathrm{N}=50)$

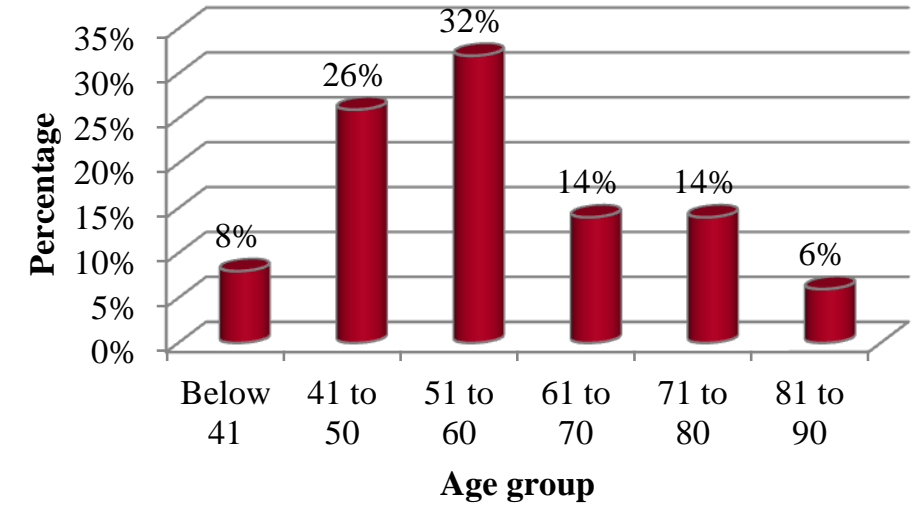

Table 2: Descriptive analysis of gender in study population $(\mathrm{N}=50)$

\begin{tabular}{|l||c||c|}
\hline Gender & Frequency & Percentage \\
\hline Male & 33 & $66 \%$ \\
\hline Female & 17 & $34 \%$ \\
\hline Total & 30 & $100 \%$ \\
\hline
\end{tabular}

Among the study population, 33 (66\%) people were male and remaining 17 (34) people were female.

Figure 2: Pie chart of gender distribution in study population $(\mathrm{N}=50)$

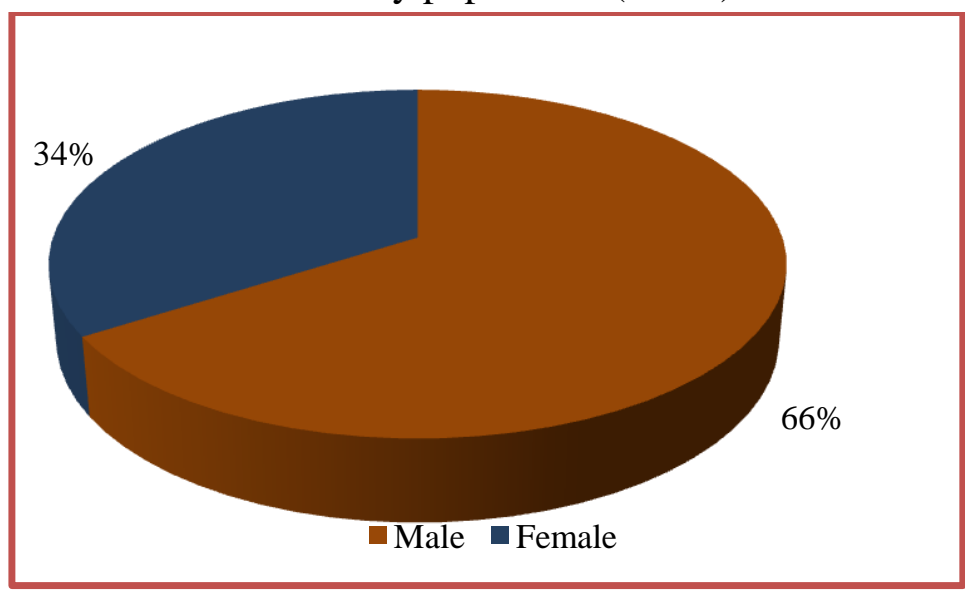

Table 3: Descriptive analysis of group in study population $(\mathrm{N}=50)$

\begin{tabular}{|l|c|c|}
\hline Study group & Frequency & Percentage \\
\hline \hline Group A & 27 & $54 \%$ \\
\hline Group B & 23 & $46 \%$ \\
\hline Total & 30 & $100 \%$ \\
\hline
\end{tabular}




\section{JMSCR Vol||07||Issue $\|10\|$ Page 677-684||October}

Figure 3: Pie chart of group in study population $(\mathrm{N}=50)$

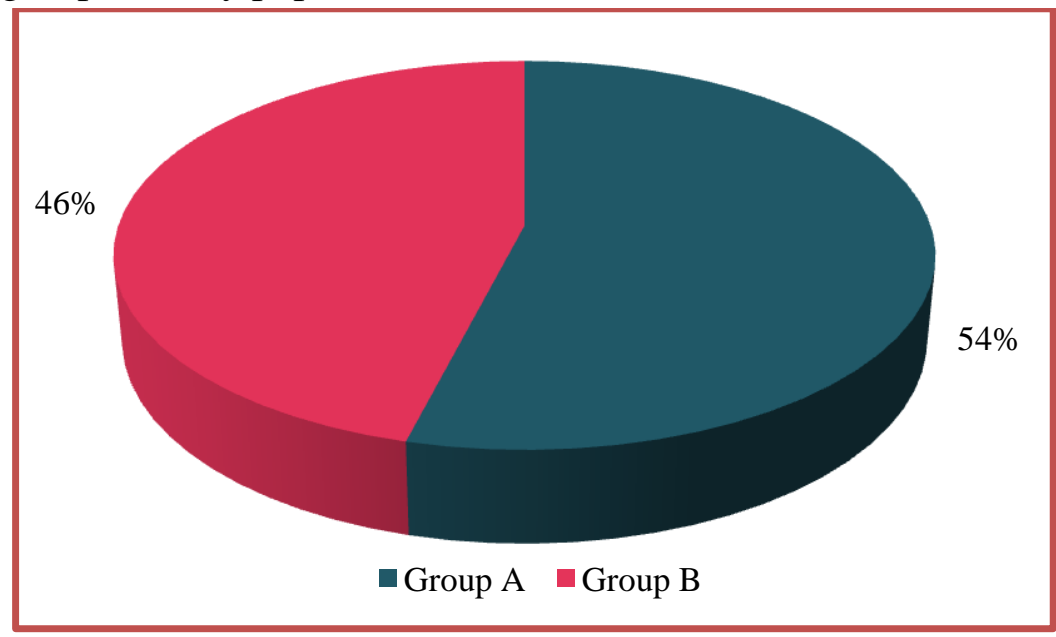

Table 4: Comparison of mean UAE between study group (N=50)

\begin{tabular}{|l|c|c|c||}
\hline \multirow{2}{*}{ Parameter } & \multicolumn{2}{|c|}{ Group } & \multirow{2}{*}{ P value } \\
\cline { 2 - 3 } & Group A (N=27) & Group B (N=23) & \\
\hline \hline UAE & $78.07 \pm 27.92$ & $17.87 \pm 6.09$ & $<0.001$ \\
\hline
\end{tabular}

The mean UAE was $78.07 \pm 27.92$ in group A and $17.87 \pm 6.09$ in group B. The difference between two groups was statistically significant $(\mathrm{P}$ value $<0.001)$.

Figure 4: Bar chart of comparison of mean UAE between study group $(\mathrm{N}=50)$

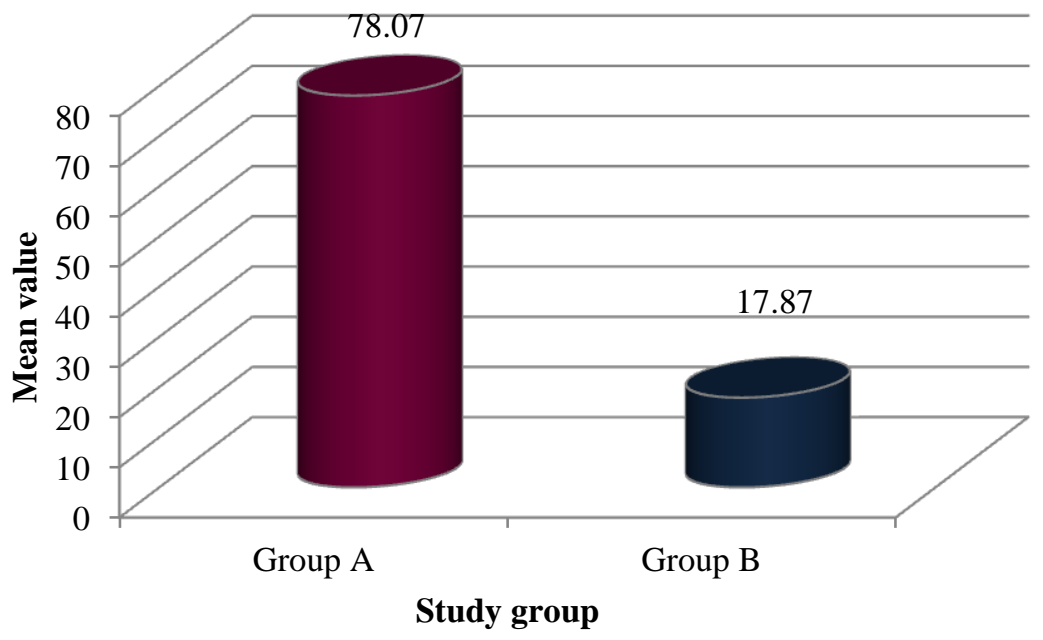

Table 5: Comparison of mean SSS between study group $(\mathrm{N}=50)$

\begin{tabular}{||l||c|c|c|}
\hline \multirow{2}{*}{ Parameter } & \multicolumn{2}{|c|}{ Group } & \multirow{2}{*}{ P value } \\
\cline { 2 - 3 } & Group A (N=27) & Group B (N=23) & \\
\hline SSS & $14.30 \pm 5.02$ & $43.09 \pm 4.98$ & $<0.001$ \\
\hline
\end{tabular}

The mean SSS was $14.30 \pm 5.02$ in group $\mathrm{A}$ and two groups was statistically significant ( $\mathrm{P}$ value $43.09 \pm 4.98$ in group B. The difference between $<0.001)$. 
Figure 5: Bar chart of comparison of mean SSS between study group $(\mathrm{N}=50)$

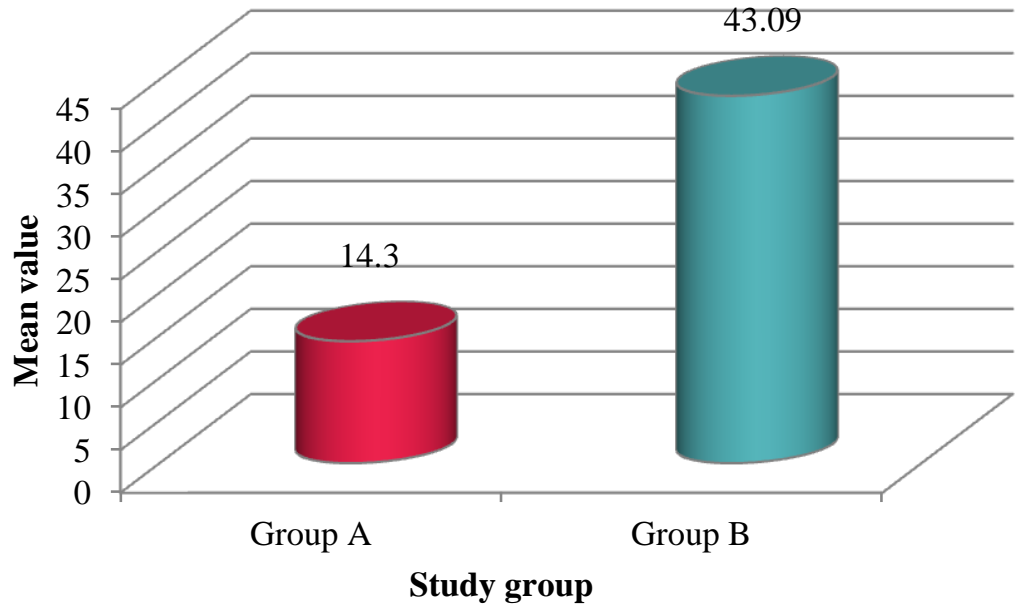

Table 6: Descriptive analysis of AGE; SBP; DBP; RBS; SSS; UAE and HbA1cin study population (N=50)

\begin{tabular}{|c|c|c|c|c|c|c|}
\hline \multirow{2}{*}{ Parameter } & \multirow{2}{*}{ Mean \pm SD } & \multirow{2}{*}{ Median } & \multirow{2}{*}{ Min } & \multirow{2}{*}{$\operatorname{Max}$} & \multicolumn{2}{|c|}{ 95\% C.I } \\
\hline & & & & & Lower & Upper \\
\hline AGE & $59.26 \pm 13.36$ & 58.00 & 40.00 & 87.00 & 55.46 & 63.06 \\
\hline SBP & $156.44 \pm 14.24$ & 151.00 & 130.00 & 190.00 & 152.39 & 160.49 \\
\hline DBP & $92.64 \pm 7.61$ & 91.00 & 78.00 & 114.00 & 90.48 & 94.80 \\
\hline RBS & $127.24 \pm 25.86$ & 126.00 & 86.00 & 178.00 & 119.89 & 134.59 \\
\hline SSS & $27.54 \pm 15.32$ & 20.00 & 4.00 & 50.00 & 23.19 & 31.89 \\
\hline UAE & $50.38 \pm 36.73$ & 42.00 & 10.00 & 152.00 & 39.94 & 60.82 \\
\hline HbA1c & $5.38 \pm 0.24$ & 5.40 & 5.00 & 5.90 & 5.32 & 5.45 \\
\hline
\end{tabular}

The mean age was 59.26 \pm 13.36 in the study population, raged between 40 to 87 (95\% CI 55.46 to 63.06).

The mean systolic blood pressure was $156.44 \pm 14.24$ in the study population, raged between 130 to 190 (95\% CI 152.39 to 160.49).

The mean diastolic blood pressure was $92.64 \pm 7.61$ in the study population, raged between 78 to 114 (95\% CI 90.48 to 94.80$)$.

The mean RBS was $127.24 \pm 25.86$ in the study population, raged between 86 to 178 (95\% CI 119.89 to 134.59$)$.

The mean SSS was $27.54 \pm 15.32$ in the study population, raged between 4 to 50 (95\% CI 23.19 to 31.89 ).

The mean UAE was $50.38 \pm 36.73$ in the study population, raged between 10 to 152 (95\% CI 39.94 to 60.80 ).
The mean HbA1c was 5.38 \pm 0.24 in the study population, raged between 5 to 5.32 (95\% CI 5.32 to 5.45$)$.

Table 7: Correlation between UAE score, age and SSS score (group A) $(\mathrm{N}=27)$

\begin{tabular}{|l||l|l||}
\hline Parameter & Person Correlation & P Value \\
\hline Age & 0.164 & 0.413 \\
\hline SSS & -0.872 & $<0.001$ \\
\hline
\end{tabular}

- There was a weak positive correlation between UAE score and age (R Value: 0.164, P value: 0.413) (Table $7 \&$ fig 6)

- There was a strong negative correlation between UAE score and SSS score (R Value: 0.872 , P value: $<0.001$ ) (Table $7 \&$ fig 7 ) 


\section{JMSCR Vol||07||Issue |10||Page 677-684||October}

Figure 6: Scatter diagram of Correlation between UAE score and Age (Group A) (N=27)

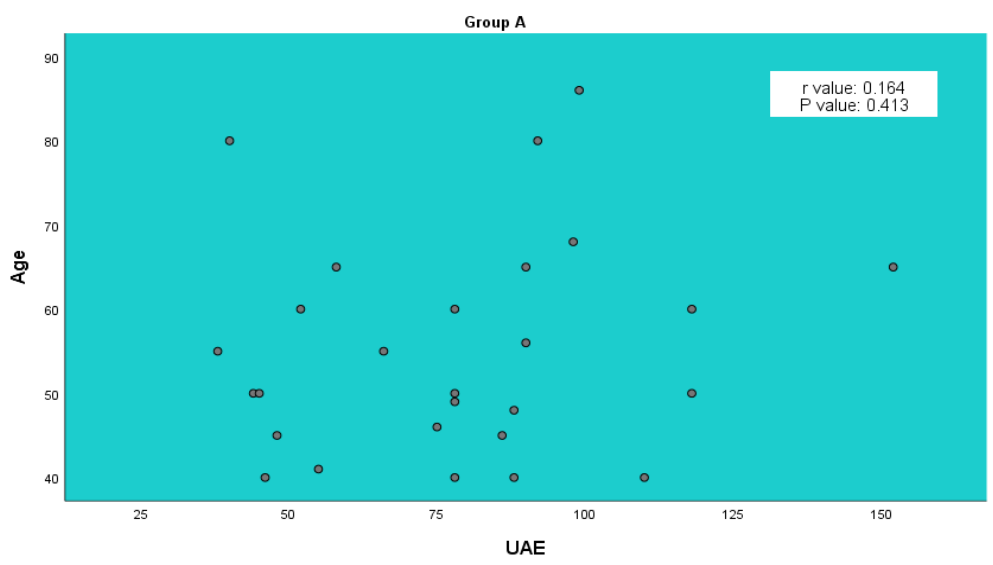

Figure 7: Scatter diagram of Correlation between UAE and SSS score (Group A) (N=27)

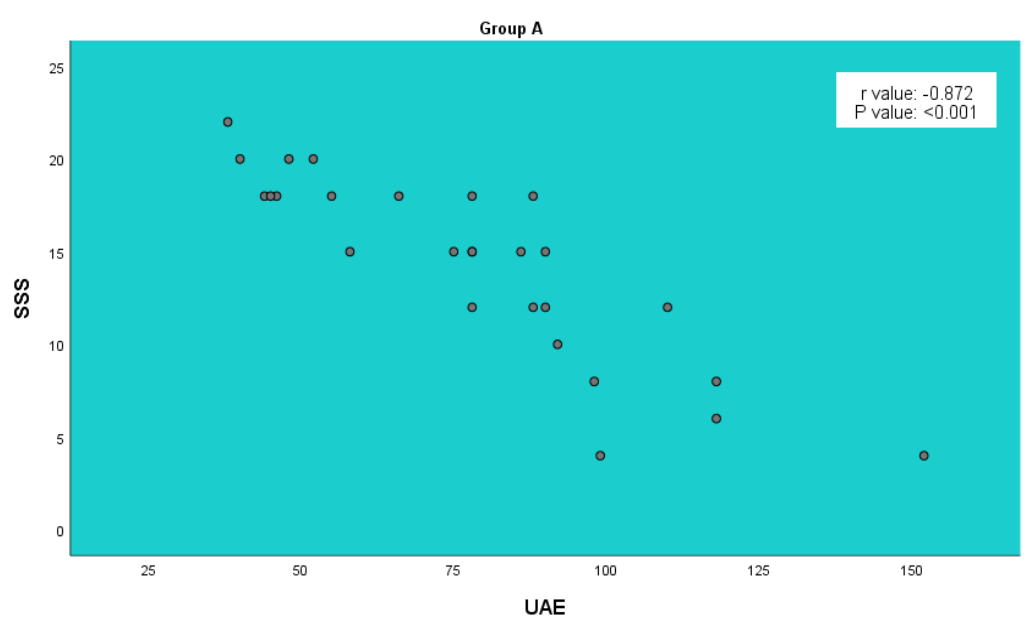

Table 8: Correlation between UAE, Age and SSS score (Group B) (N=23)

\begin{tabular}{||l||c|c||}
\hline Parameter & Pearson Correlation & P value \\
\hline \hline Age & 0.424 & 0.044 \\
\hline SSS & -0.490 & 0.018 \\
\hline
\end{tabular}

There was a weak positive correlation between UAE score and age( $\mathrm{R}$ Value: $0.424, \mathrm{P}$ value: 0.044 ) (Table 8 \& fig 8)

There was a weak negative correlation between UAE score and SSS score(R Value: $-0.490, \mathrm{P}$ value: 0.018) (Table 8 \& fig 9)

Figure 8: Scatter diagram of Correlation between UAE score and Age (Group B) $(\mathrm{N}=23$ )

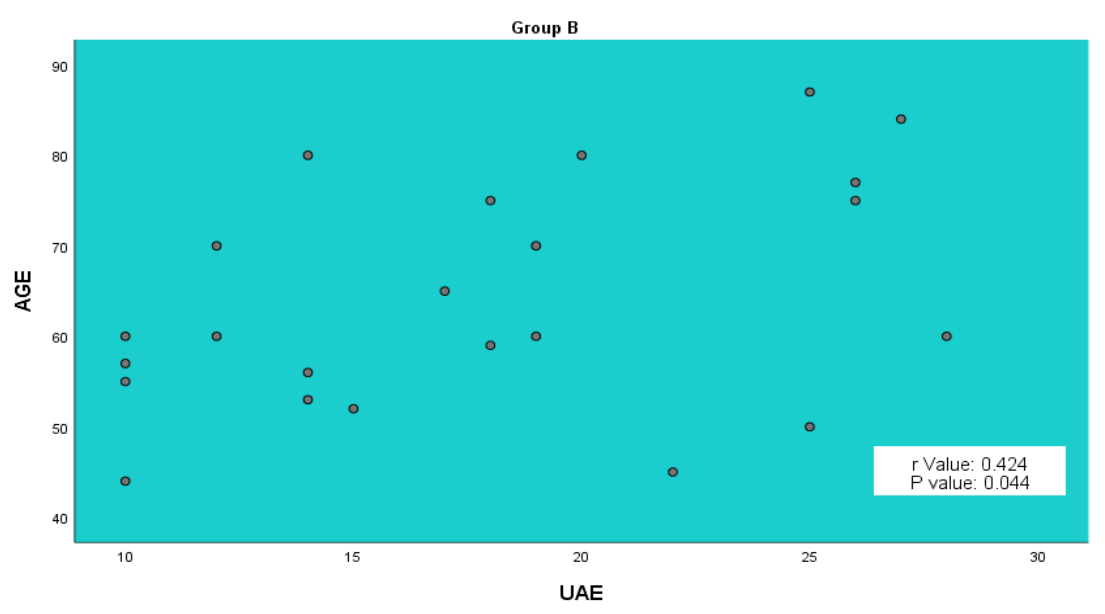


Figure 9: Scatter diagram of Correlation between UAE score and SSS score (Group B) (N=23)

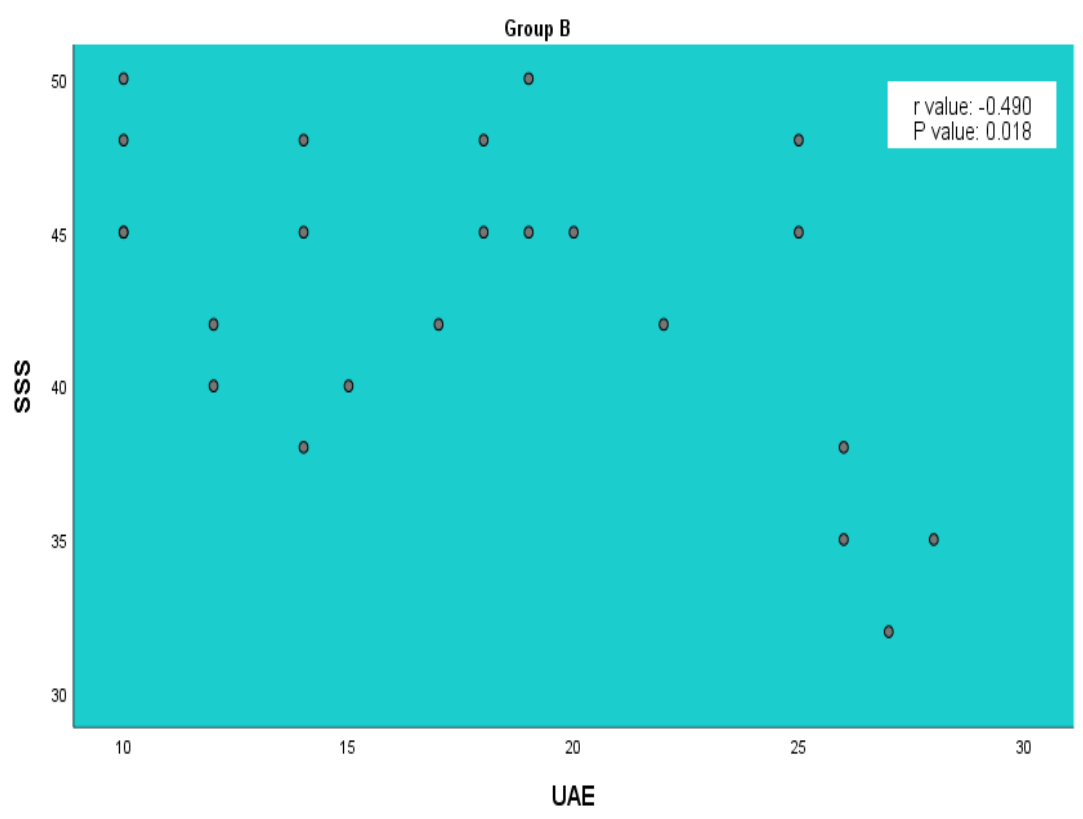

\section{Results}

The study group included 50 patients. Microalbuminuria was present in 27 of the 50 patients. The study group was again divided into two basic groups.

Group A-Patients with Microalbuminria

Group B-Patients without Microalbuminria

The baseline characteristics of the patients with Microalbuminuria and patients without Microalbuminuria are compared. These two groups were mainly compared in terms of their Age, Gender, SSS, Blood Pressure, Blood Sugar.

\section{Discussion}

The association of Microalbuminuria in cerebrovascular diseases has been confirmed in a few Western studies. This study was undertaken to analyze Microalbuminuria in acute cerebral ischemic events in our context. $^{3,4}$

\section{Conclusion}

Microalbuminuria was present in 54\% acute ischemic stroke patients studied. Urine albumin excretion had the strongest correlation with the Scandinavian Stroke Scale of the patient in Acute Ischemic Stroke. Those with a lower Scandinavian Stroke Scale had a higher rate of urine albumin excretion and vice versa. Acute ischemic stroke patient with Microalbuminuria were significantly older than Normalbuminurics but there was no significant graded correlation of Age with urine albumin excretion in inter-group and intra-group studies. There was no significant difference in Blood Pressure in Microalbuminurics and Normalbuminurics. There was no significant correlation of Blood Pressure with Urine Albumin Excretion in acute ischemic stroke.

\section{Reference}

1. Yudkin JS, Forest RD, Jackson CA - Microalbuminuria as a predictor of vascular disease in non-diabetic subje cts. Isling-ton diabetics survey, Lan cet, 1988; 2; 530- 533.

2. Gupta DK, Verma LK, Prevalence of Microalbuminuria in Indian Diabetics: Indian J Nephro 1991: 51-61.

3. Jalal S, Sofi FA, Alai MS, Siddiqqi MA, Bhat MA, Khan KA, Jan VML one NA, Rather AA: Prevalence of $M$ icroalbu-minuria in Essential Hypert ension: Indian J Nephrology:2001;11: 6-11.

4. Barmer NB, Coull BM, Clark WM, Wyan M: Microalbu-minuria in Isch 
emic stroke: Arch Neurol, 1999;56;69 9-702.

5. Turaj W, Slowik A, Wyrwicz-Petkow U, Pankiewicz J, Iskra T, Rudzinska M , Szczudlik A; Prognostic significan ce of Microalbumunuria in non-diabet ic stroke:Med Sci Monit,2001;7(5); 98 9-994. 